\title{
Subacute Infective Endocarditis in a Child Due to Streptococcus acidominimus: a Case Report
}

\author{
Streptococcus Acidominimus'in Sebep Olduğu \\ Subakut Enfektif Endokarditli Çocuk Olgu
}

\author{
Ayşe Sülü'(ID), Ümmühan Çay²(iD), Hikmet Öztel Ocak(iD) \\ ${ }^{1}$ Clinic of Pediatric Cardiology, Aydın Maternity and Children's Hospital, Aydın, Turkey \\ ${ }^{2}$ Clinic of Pediatric Infectious Diseases, SBÜ Adana City, Adana, Turkey \\ ${ }^{3}$ Clinic of Medical Microbiology, Trabzon Kanuni Training and Research Hospital, Trabzon, Turkey
}

Cite this article as: Sülü A, Çay Ü, Öztel Ocak H. Subacute infective endocarditis in a child due to Streptococcus acidominimus: a case report. J Pediatr Inf 2020;14(4):e225-e228.

\section{Abstract}

Streptococcus acidominimus is rarely pathogenic in humans and is usually detected in veterinary science. In the literature, there are approximately 20 case reports that Streptococcus acidominimus is a human pathogen. They are pneumonia, pericarditis, infective endocarditis, sepsis, brain abscess and gradienigo syndrome. Only two of these cases were in the pediatric age group, one was infective endocarditis at the age of 15 years, other one was otitis media and gradenigo syndrome at the age of 12 years. There are no cases of invasive infection due to Streptococcus acidominimus in Turkey. Here, we report a case of infective endocarditis caused by Streptococcus acidominimus at 14 years of age.

Keywords: Streptococcus acidominimus, infective endocarditis

\section{Introduction}

Streptococcus acidominimus is a Gram-positive, spherical, short-chained, catalase-negative and weak facultative anaerobic microorganism (1). As a coccus of the viridans streptococci group, it is rarely detected as a pathogen in humans. It is generally considered a bacterial pathogen in the field of veterinary medicine (2-4). S. acidominimus was first isolated by Ayers and Mudge (5) in 1922 from bovine sources. Limited
Öz

Streptococcus acidominimus insanlarda nadiren patojen olup genellikle veterinerlik biliminde tespit edilmektedir. Literatürde Streptococcus acidominimus'un patojen olduğu pnömoni, perikardit, enfektif endokardit, sepsis, beyin apsesi ve gradienigo sendromu bildirilen yaklaşık 20 kadar olgu sunumu mevcuttur. Bu olgulardan sadece iki tanesi pediatrik yaş grubunda olup birisi 15 yaşında enfektif endokardit, diğeri 12 yaşında otitis media ve gradenigo sendromudur. Ülkemizden Streptococcus acidominimus'a bağlı invazif enfeksiyon bildirilen olgu yoktur. Biz burada 14 yaşında Streptococcus acidominimus'un neden olduğu enfektif endokarditli olgumuzu sunduk.

Anahtar Kelimeler: Streptococcus acidominimus, enfektif endokardit

number of pneumonia, pericarditis, brain abscess, meningitis, peritonitis, and sepsis cases of $S$. acidominimus have been reported in humans $(3,4,6-8)$. Despite being rare in children, infective endocarditis (IE) is observed more frequently in the event that an underlying heart disease exists. Along with isolating Staphylococcus aureus and viridans group streptococci typically as agents, there has been an increase in the frequency of uncommon microorganisms in recent years. 
Cases with invasive infection related to $S$. acidominimus are mostly seen in the adult age group; however, a couple of pediatric cases have also been reported. Until today, there has only been one pediatric case reported with subacute infective endocarditis in the literature, and there is no case reported from our country (7). This study aimed at reporting a 14-yearold case with subacute infective endocarditis due to S. acidominimus. This is the first case from our country to report $S$. acidominimus- related invasive infection.

\section{Case Report}

A 14-year-old male patient presented with fever ongoing for 10 days. The patient had no known history of prior disease, animal contact and dental intervention. Physical examination revealed body weight as $32 \mathrm{~kg}(<3$ percentile) and height as $144 \mathrm{~cm}$ ( $<3$ percentile). The patient appeared pale and cachectic. Cardiac apex beat was 120/min, blood pressure $110 / 70 \mathrm{mmHg}$, respiratory rate $20 / \mathrm{min}$, and body temperature $37.3^{\circ} \mathrm{C}$. The patient had distinct $3 / 6$ systolic ejection murmur and diastolic murmur in the aortic area. Under his jeans, the spleen was 3-4 cm palpable and traube closed. The liver was non-palpable. Splinter hemorrhage was present in three toes on the right foot. Electrocardiography showed left axis deviation, left ventricle hypertrophy, and T negativity in AVF. No changes were seen in the ST segment. On electrocardiography performed with a preliminary diagnosis of infective endocarditis, the left ventricle was hypertrophic, IVSd: $10.2 \mathrm{~mm}$ (z score: 4.75), and LVPWd: $9.5 \mathrm{~mm}$ (z score: 2.67$)$. The aortic valve was found bicuspid and thin, and the aortic anulus narrow: $14 \mathrm{~mm}$ (z score: -1.94). A 9x6 mm appearance compatible with hyperechogenic vegetation at the aortic valve mitral junction extending to the ventricle was present. A $14 \times 8 \mathrm{~mm}$ hyperechogenic appearance in the aortic mitral continuity was seen, and the mitral valve septal leaflet was thin. Moderate-severe stenosis forming maximum 52 mean $35 \mathrm{mmHg}$ gradient in the aortic valve and 3rd degree aortic insufficiency were present. 3 rd degree insufficiency was present in the mitral valve. Complete blood count of the patient was as follows: hemoglobin $10.2 \mathrm{~g} / \mathrm{dL}$, white blood cell count $5.400 \mathrm{~mm}^{3}$, platelet $100.000 \mathrm{~mm} 3$, peripheral smear $65 \%$ neutrophil, C-reactive protein $1.72 \mathrm{mg} / \mathrm{dL}$, erythrocyte sedimentation rate $25 \mathrm{~mm} / \mathrm{h}$; patient's biochemical parameters were normal, complete urine test was normal, and anteroposterior chest radiography was normal. No finding compatible with infective endocarditis ophthalmologic involvement was detected in ophthalmologic examination. No pathology other than splenomegaly was confirmed on abdominal ultrasonography. The patient was admitted with a preliminary diagnosis of infective endocarditis with the current findings, and repetitive blood cultures were taken in accordance with the pediatric infective endocarditis guideline (8) of the American Heart
Association. The patient, who had 1 major and 3 minor criteria of the modified Duke criteria, was initiated empirical ceftriaxone, vancomycin, and gentamycin treatment with a definitive diagnosis of infective endocarditis. Patient's fever was under control at the $48^{\text {th }}$ hour of treatment. Blood samples inoculated at the blood culture medium were incubated in the BacT/ALERT 3D automatized culture system (Biomerieux, the USA). In addition to conventional methods, the bacterium that grew was defined as S. acidominimus at the species level with MALDI-Biotyper (Bruker, Germany). Antimicrobial sensitivity tests were determined by Phoenix 100 (Becton Dickinson Diagnostic Instrument Systems, Sparks, the USA) automatized system and the disk diffusion method. S. acidominimus growth was detected in two of the three blood cultures taken prior to antibiotherapy. No growth was detected in the control blood cultures taken later on. On the seventh day of treatment, antibiogram showed susceptibility to cefepime, vancomycin and teicoplanin, moderate susceptibility to penicillin $\mathrm{G}$, and resistance to cefotaxime. Simultaneously, upon the recurrence of elevated fever $\left(38.5^{\circ} \mathrm{C}\right)$, it was seen that CRP was slightly increased $(2.18 \mathrm{mg} / \mathrm{dL})$ and platelet count was decreased to $65.000 \mathrm{~mm}^{3}$, and considering the result of the culture antibiogram, ceftriaxone was stopped and cefepime was started on the patient taking into account an infection related to healthcare services. Patient's fever was taken under control during follow-up. Magnetic resonance imaging was performed on the hip and thigh with a preliminary diagnosis of septic embolism and osteomyelitis due to pain and limited motion on the right hip on the $16^{\text {th }}$ day of admission. Osteomyelitis was ruled out with the current findings of the patient who was also evaluated by orthopedics. Regarding the findings of magnetic resonance imaging, soft tissue infection was considered. Complaints and acute phase reactants of the patient regressed with nonsteroid anti-inflammatory treatment. Antibiotherapy of the patient whose control blood cultures did not show growth was completed in 6 weeks. Control echocardiography did not show any change in the vegetation appearance, and thus it was reviewed as organized calcified vegetation. The patient was referred to an advanced center to be evaluated in terms of aortic valve surgery following discharge.

\section{Discussion}

While the estimated annual pediatric IE incidence in the United States of America is 3.3 in 100.000 under the age of 12 months, it ranges between 0.3 and 0.8 per 100.000 in adolescents and children (9). Infective endocarditis is the infection of the heart valves, endocardium, and vessel endothelium caused by various microorganisms including mainly bacteria and less frequently fungi, viruses, chlamydia and rickettsia. Although infective endocarditis can be caused by various 
pathogenic microorganisms, the most common pathogens of IE in children are types of staphylococci and streptococci. It has been shown in patients with underlying diseases that the agents include $28 \%$ S. aureus, $7 \%$ other types of staphylococci, $33 \%$ viridans group streptococci, $17 \%$ other streptococci, $5 \%$ gram-negative bacilli, and $11 \%$ polymicrobial microorganisms (10). Recently, there has been an increase in the number of infective endocarditis cases related to uncommon pathogens. S. acidominimus, a type of streptococcus, can be easily differentiated from other types. It is most commonly isolated from the vaginal mucosa and raw milk of cows. Despite being frequently encountered in farm animals, it can be rarely isolated in humans from the wound site, urine, lungs, inner ear, and cerebrospinal fluid $(1,5)$. It has been isolated in a limited number of cases as a disease agent in the literature. The number of cases in the pediatric age group with a diagnosis of infective endocarditis is substantially low.

Criteria of infective endocarditis have been determined as modified Duke criteria (11). Our patient showed 1 major and 3 minor criteria at the beginning and was considered in the positive infective endocarditis group, and upon having growth in blood culture, the major criteria of the patient raised to 2 .

In the literature, approximately 20 cases related to S. acidominimus have been reported. These cases are invasive infections such as pneumonia, pericarditis, brain abscess, meningitis, peritonitis, endocarditis, sepsis, and otitis media (gradenigo's syndrome) $(3,4,6-8)$. Two of these are in the pediatric age group $(7,12)$. The first of these patients was a 15 -yearold case followed for ventricular septal defect and presented with subacute IE due to S. acidominimus and treated successfully by Brachlow and colleagues (7). The other pediatric case, reported by Finkelstein and colleagues (12), was a 12-year-old patient who had no underlying disease but otitis media, Gradenigo's syndrome and in whose pus culture obtained by tympanocentesis, S. acidominimus was isolated. The patient was successfully treated with long-term antibiotic treatment. Our case is the first in our country and third in the literature and did not have any animal contact just like in the other cases. Our case presented with high fever, similar to the other cases. Although the cases reported in the literature presented acute with a severely toxic clinical picture, our case presented subacute with good general condition and stable vital signs. Peripheral findings were not observed in the other pediatric infective endocarditis case in the literature and were associated with rarely seen agents. Dissimilarly to the literature, our case had mild clinical findings and splinter hemorrhage. Moreover, the soft tissue infection seen on the $16^{\text {th }}$ day of treatment was considered to be related to septic embolism. In addition, in comparison to the case series reported by Wu et al. (6), our patient did not have any additional complaints other than fever and was clinically stable. Despite a 10-day fever history, the vegetation seen in echocardiography was calcified and organized. Patient history did not reveal any clinical deterioration, history of fever, animal contact, dental intervention, antibiotic use, and history of hospitalization.

Even though the first cases of S. acidominimus were beta-lactam susceptible, recent cases have reported resistance to beta-lactam group antibiotics (6). In our case, penicillin was found moderately susceptible; cefuroxime, cefotaxime, and ceftriaxone were found resistant, and gentamicin, cefepime, clindamycin, and vancomycin were found susceptible. Having arranged the treatment according to the antibiogram, it was completed in 6 weeks.

Appropriate cultures must be taken in cases considered to have infective endocarditis, and rarely seen microorganisms must be taken into account. Differences in clinical course can be seen with these microorganisms. Since the frequency of rarely-seen microorganisms has increased and a change in their antibiotic susceptibilities has been established in recent years, antibiogram must be performed considering the preliminary diagnosis, and treatment must be planned according to the result of the antibiogram test.

Informed Consent: Patient consent was obtained.

Peer-review: Externally peer-reviewed.

Author Contributions: Concept - AS, ÜÇ; Design - AS, ÜÇ; Supervision - AS, ÜÇ; Resources - AS, ÜÇ; Data Collection and/or Processing - AS, ÜÇ, HÖO; Analysis and/or Interpretation - AS, ÜÇ, HÖO; Literature Review - AS, ÜÇ; Writing - AS Critical Review - AS, ÜÇ.

Conflict of Interest: No conflict of interest was declared by the authors.

Financial Disclosure: The authors declared that this study has received no financial support.

\section{References}

1. Smith FR, Sherman JM. Streptococcus acidominimus. J Infect Dis 1939;65:301-5. [CrossRef]

2. Siegman-Igra $Y$, Azmon $Y$, Schwartz D. Milleri group Streptococcus- $a$ step child in the viridans family. Eur J Clin Microbiol 2012;3:2453-9. [CrossRef]

3. Baker L, Carlson R. Streptococus acidominimus isolated from a multiloculated empyema in a critically ill adult man with pneumonia case report and review of literature. Heart Lung 2008;37:308-10. [CrossRef]

4. Akaile $T$, Suga $M$, Ando $M$, Ando $Y$, Araki S, Fujise R. Streptococcus acidominimus infections in a human. Jpn J Med 1988;27:317-20. [CrossRef]

5. Ayers SH, Mudge CS. The Streptococci of the bovin eudder. IV. Studies of streptococci. J Infect Dis 1922:31;40. [CrossRef]

6. Wu C, Liang B, Gong Y, Zhang L, Zou Y, Ge J. Streptococcus acidominimus causing invasive disease in humans: a case series. J of Med Case Reports 2014;8:57. [CrossRef] 
7. Branclow A, Awadallah S, Chatterjee A. Endocarditis due to streptococcus acidominimus. Pediatr Cardiol 2003;24:161-3. [CrossRef]

8. Cone LA, Etebar S, Waterbor RB. Brain abscess due to Streptococcus acidominimus: first case report. Surgical Neurology 2007;67:296-7. [CrossRef]

9. O'Brien SE. Infective endocarditis in children. Available from: http:// www.uptodate.com/contents/infective-endocarditis in children. Access date: April 2018. [CrossRef]

10. Gupta S, Sakhuja A, McGrath E, Asmar B. Trends, microbiology, and outcomes of infective endocarditis in children during 2000-2010 in the United States. Congenit Heart Dis 2017;12:196. [CrossRef]
11. Baltimore RS, Gewitz $M$, Baddour $L M$, Beerman $L B$, Jackson $M A$, Lockhart PB, et al. Infective endocarditis in childhood:2015 Update, $A$ Scientific Statement From the American Heart Association. Circulation 2015;132:1487-515. [CrossRef]

12. Finkelstein $Y$, Marcus N, Mosseri R, Bar-Sever Z, Garty BZ. Streptococcus acidominimus infection in a child causing Gradenigo syndrome. Int $J$ Pediatr Otorhi 2003;67:815-7. [CrossRef] 